\title{
Improving left ventricular assist devices: Engineer to decrease the shear
}

\author{
Ming-Sing Si, MD \\ From the Section of Pediatric Cardiovascular Surgery, Department of Cardiac Surgery, University of Michigan, \\ Ann Arbor, Mich. \\ Disclosures: Author has nothing to disclose with regard to commercial support. \\ Received for publication Aug 4, 2018; accepted for publication Aug 10, 2018; available ahead of print Sept 26, \\ 2018. \\ Address for reprints: Ming-Sing Si, MD, 11-735 C.S. Mott Children's Hospital, SPC 4204, 1540 E Hospital Dr, \\ Ann Arbor, MI 48109-4204 (E-mail: mingsing@umich.edu). \\ J Thorac Cardiovasc Surg 2019;157:602 \\ $0022-5223 / \$ 36.00$ \\ Copyright $(2) 2018$ by The American Association for Thoracic Surgery \\ https://doi.org/10.1016/j.jtcvs.2018.08.029
}

The Heartmate 3 (HM3; Thoratec Corporation, Pleasanton, Calif), the latest generation of left ventricular assist device (LVAD), is a centrifugal pump that uses magnetic levitation and larger blood flow gaps, which have resulted in reduced shear stress on the components of the circulating blood and decreased risk of pump thrombosis. ${ }^{1,2}$ According to the principles of pump fluid mechanics, smaller axial flow pumps usually require greater rotational speed to compensate for a rotor with a smaller diameter relative to a centrifugal pump with a larger rotor. ${ }^{3}$ It is thus not surprising that a centrifugal pump LVAD (EVAHEART; Evaheart, Inc, Houston, Tex) has a superior hemocompatibility profile to that of the last generation axial pump LVAD, the Heartmate II (Thoratec). ${ }^{4}$

In this issue of the Journal, Zayat and colleagues ${ }^{5}$ present an in vitro comparison of the hemocompatibility characteristics of the HM3 and the EVAHEART centrifugal pump LVADs. The EVAHEART device is a hydraulically levitated centrifugal pump with even larger blood flow gaps, and there has also been some clinical experience with this LVAD. $^{6}$ Zayat and colleagues ${ }^{5}$ investigators used an in vitro mock loop to compare the hemocompatibility profiles of the HM3 and the EVAHEART devices with human blood isolated from volunteer subjects. With their in vitro mock loop platform, they found that the EVAHEART device demonstrated decreased hemolysis, decreased activation of coagulation system, and preserved von Willebrand factor function relative to the HM3.

The exact rotor dimensions and designs of both pumps are not disclosed. Zayat and colleagues ${ }^{5}$ do mention, however, that the external dimensions of both are similar, with the EVAHEART being slightly larger in diameter. Importantly, the EVAHEART operates at a lower rotation speed than the HM3 and uses more power, although the efficiencies of both pumps are not mentioned. We can only surmise that the diameter of the EVAHEART rotor is characteristics.

\section{References} 2015.

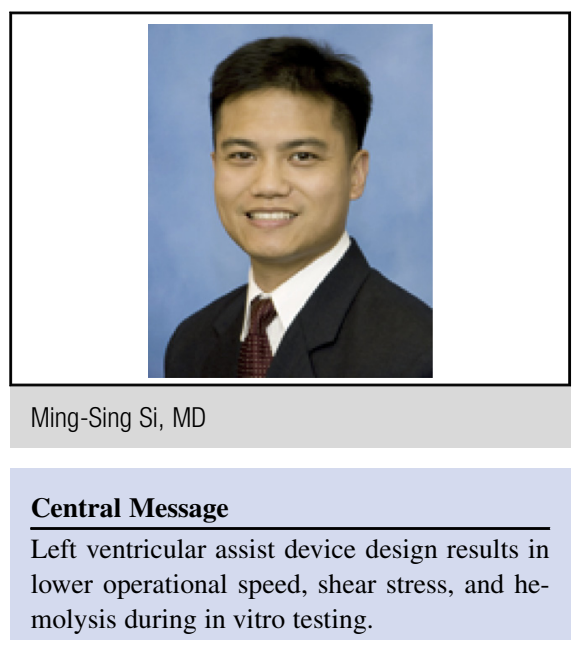

See Article page 591.

minimally larger than that of the HM3, and thus the lower operational speed of the EVAHEART may be attributed to a superior rotor design.

The EVAHEART uses what appears to be a more complicated and cumbersome hydraulic levitation that requires the circulation of sterile water. The advantage of this type of levitation system relative to the magnetic levitation used in the HM3 is not well defined. Nonetheless, what can be gained from the results of Zayat and colleagues $^{5}$ is that improvement in pump rotor design can decrease the shear and improve LVAD hemocompatibility

1. Schmitto JD, Hanke JS, Rojas SV, Avsar M, Haverich A. First implantation in man of a new magnetically levitated left ventricular assist device (HeartMate III). J Heart Lung Transplant. 2015;34:858-60.

2. Mehra MR, Naka Y, Uriel N, Goldstein DJ, Cleveland JC Jr, Colombo PC, et al; MOMENTUM 3 Investigators. A fully magnetically levitated circulatory pump for advanced heart failure. $N$ Engl J Med. 2017;376:440-50.

3. Janna WS. Introduction to Fluid Mechanics. 5th ed. Boca Raton (FL): CRC Press;

4. Bartoli CR, Kang J, Zhang D, Howard J, Acker M, Atluri P, et al. Left ventricular assist device design reduces von Willebrand factor degradation: a comparative study between the HeartMate II and the EVAHEART left ventricular assist system. Ann Thorac Surg. 2017;103:1239-44.

5. Zayat R, Moza A, Grottke O, Grzanna T, Fechter T, Motomura T, et al. In vitro comparison of the hemocompatibility of two centrifugal left ventricular assist devices. J Thorac Cardiovasc Surg. 2019;157:591-9.e4.

6. Matsumoto Y, Fujita T, Fukushima S, Hata H, Shimahara Y, Kume Y, et al. Comparison of hemodynamic performance and clinical results with EVAHEART versus HeartMate II. ASAIO J. 2017;63:562-7. 